\title{
Gravity mission to launch
}

The planned launch next week of GOCE, a satellite designed to measure Earth's gravity field in unprecedented detail, will bolster the fields of geodesy, oceanography and climate prediction, scientists hope.

Part of the European Space Agency's Living Planet Programme, GOCE - for Gravity field and steady-state Ocean Circulation Explorer is scheduled for launch on 16 March from the Plesetsk Cosmodrome in Russia, using a converted Russian SS-20 missile. Problems with its upper-stage navigation system delayed the launch from last September.

Over its expected lifetime of 20 months, GOCE will map tiny variations in Earth's gravity field that stem from the position of mountains and ocean trenches, and from small density variations in the planet's interior. Three pairs of cube-shaped accelerometers, in free fall inside the satellite, will make the measurements at five times the precision of GRACE, the US-German Gravity Recovery and Climate Experiment that has been orbiting Earth since 2002. The two missions are complementary; GOCE provides much better resolution at the small scale, whereas GRACE can show larger-scale trends, such as how gravity changes as ice sheets melt or gain mass.

\section{Permanent record}

At a cost of $€ 350$ million (US\$442 million), GOCE will determine the Earth's geoid - an idealized surface representing a level, motionless ocean - with an accuracy of 1-2 centimetres and at a spatial resolution of better than 100 kilometres. The data should enable scientists to map sea level better and to determine mean ocean circulation. "Until now, we could measure only the variable component of ocean currents such as the Gulf Stream, whereas the permanent part remained unknown," says Marine Herrmann, an oceanographer at the National Centre for Meteorological Research in Toulouse, France.

The data should also help to inform discoveries from other satellites, such as the Jason series that measures sea-level variation to deduce factors such as ocean convection.

With the geoid as a reference, scientists should be able to differentiate between signals due to climate change and those due to natural fluctuations in ocean circulation. "The ocean is the memory of the climate system," says Jochem Marotzke, an oceanographer at the Max Planck Institute for Meteorology in Hamburg, Germany. "Our goal is to make decadal climate prediction, but to do this you need to know the initial state of the ocean."

Computer models will still be needed to translate the strength of surface flows into the larger dynamics of ocean circulation. But much can be deduced from space. For instance, the intensity of deep convection - the process by which cold water sinks to depth - is related to sea surface elevation and can be monitored, at least approximately, from space . $^{1}$

"The surface itself tells you a lot," says Chris Hughes, from the Proudman Oceanographic Laboratory in Liverpool, UK, and a member of the GOCE mission advisory group. Earlier this year, Hughes showed that the sea level off the east coast of North America contains a signal of the strength of the Atlantic overturning circulation ${ }^{2}$. Gravity data will help to improve such estimates, he says.

GOCE's maximum lifetime is limited to two years, because it needs to fly at an altitude of 270 kilometres (compared with GRACE's initial 500 kilometres) to measure gravitational changes so precisely, and extra fuel is needed to compensate for the drag the atmosphere exerts at that low elevation.

Meanwhile, the successor to the current Jason-2 altimetry mission, Jason-3, remains some $€ 60$ million
unding. The European Organisation for the Exploitation of Meteorological Satellites, one of the partners for Jason-3, plans to meet on 1 July to discuss how to divide up that shortfall between its member countries.

Quirin Schiermeier

1. Herrmann, M., Bouffard, J. \& Béranger, K. Geophys. Res. Lett. 36, L03606 (2009)

2. Bingham, R. J.\& Hughes, C. W. Geophys. Res. Lett. 36, L02603 (2009). 